\title{
Transformation of Product Characteristics in Terms of an Integrated Management System
}

\author{
Lukáš Kamenický*, Štefan Markulik and Juraj Sinay
}

Technical University of Košice, Faculty of Mechanical Engineering, Department of Safety and Quality, Letná 9, 04200 Košice,

Slovak Republik

\section{BIOGRAPHICAL NOTES}

Lukáš Kamenický, Ing., born 1st May 1988, graduated from the Technical University of Kosice, Faculty of Mechanical Engineering, in the field of Quality production engineering, in 2012. Current position: PhD student. Specialization: Integrated management systems. He has written more than 10 publications in the area of integrated management systems and quality production.

Štefan Markulik, doc. Ing., PhD., born 10th August 1976, graduated from the Technical university of Košice, Faculty of Mechanical Engineering, in the field of quality production, in 2001. Current position: Assistant Professor. Specialization: quality management system, audit and implementation of quality management system, quality in higher education area. He has written more than 60 publications in the area of quality management, and participated as a team member in several national and international projects.

Juraj Sinay, DrSc., prof., Ing., PhD., born $18^{\text {th }}$ December 1949; graduated from the Technical University of Košice, Faculty of Mechanical Engineering in 1973. Position: Professor, Head of the Department of Quality and Safety; Specialization: Risk management, Occupational safety and health, and Safety of technological systems. Member of the working group IVSS, Sektion Maschinenschutz based in Manheim, Germany. Member of Gesellschaft für Sicherheitswissenschaften (Society for Safety Sciences) VDI Wuppertal, Germany. Member of the Conference of German-speaking Professors of Transport Technology in Europe based in Berlin, Germany. He has authored several professional publications on occupational safety and management of risks related to machines and devices in the safety and security interface, and papers for numerous journals and conferences.

\section{KEY WORDS}

Integrated management systems, Demand Compliant Design, requirements, product development.

\section{ABSTRACT}

This paper introduces an approach for collecting requirements of products and an integrated management system and subsequently links them by use of organizational processes and structures. More specifically this is a unique and integrated approach for IMS, Requirement Management and product design. This approach supports organizational processes with methods and tools helping to analyze, control and primary build up and handle complex systems and the interdependencies between their comprising models from various domains within the range of integrated management sys- 
tems. Duplicity or contradictions of requirements can be avoided. This approach links requirements of product models with integrated management systems by using the modeling method Demand Compliant Design as a data base. Its aim is to create a methodology to improve organizational processes and create synergies. By considering the basic rules of operational and organizational structures the guidelines for product liability can be fulfilled and the legal risk for the company can be reduced.

\section{Introduction}

Every organization, regardless of the subject of its activity, makes an effort to meet their customer's requirements related to the products they offer. Only satisfied customers can help the company to generate profit, and profit is an important factor for the further development of the organization. The organization's development can involve, for instance, investing in employees by creating ergonomic and safe workplaces and social environment, developing their skills, investing into the development of production facilities and lastly the product innovation. This can be achieved by quality management in the product creation phase, which is an integral part of the overall management within an organization. Various approaches are used to promote quality management in practice, such as Lean, Kaizen, Six-Sigma, alongside with integrated management systems according to standards ISO 9001, OHSAS 18001, ISO 14001, etc. The utilization of the integrated management system in practice is not limited to implementing the quality requirements; it also includes proactive management of occupational safety and health and other management system requirements.

\section{Integrated management system in an organization}

By integrating Quality management system (QMS) and the Occupational Health and Safety Management System (OH\&SMS), organizations want to demonstrate its commitments to customers, as well as employees, in the context of sustainable development and production product regarding the legislator. It is given that the product safety, but also the production technology safety is one of the quality components, which is defined by the directive of European Union 2006/42/EU and from them derived legal regulations of each countries of the European Union [5]. Given the historical development of management concepts, structure of standards, accountability of senior management and organizational culture, there is a high degree of integration of these systems. This means interlinking the customer-oriented and employee-oriented systems into a single unit, which is related to the fulfillment of objectives based on the common policy. At the end there should me a transfer of all requirements regarding a product to organizational processes and integrated management system. This can be accomplished by modeling those requirements. On the one hand modeling the requirements of the product and the product itself and on the other hand modeling the organizational processes and the related requirements so that in the end everything is included into the IMS. In order to do this, IMS have to be used as a generic approach. And this is driven by a new culture.

\subsection{Modeling of IMS by using software}

The newest information technologies allow creating a digital manufacturing. These software programs are a comprehensive portfolio of digital manufacturing solutions that deliver innovation by linking all manufacturing disciplines together with product engineering - from process layout and design, process simulation and validation, to manufacturing execution. One software program, used for this paper called QUAM. This software program is focuses on integrated management system modeling which intelligently links Operational Processes, Human Activities and Organizational Structure, while complying with internal and external rules. This software offering solution on basic organizational modeling questions like:

\section{- What is a structure of the company?}

- How are the processes designed?

- What is the working communication like across operational and organizational structure within the organization?

\section{- How are the rules and regulations fulfilled?}

Once all processes are modeled and documented, the organization's data and its corresponding work flow charts can be analyzed and optimized. This procedure ultimately leads to reduction of costs, higher effectiveness, and leaner production for organizations. All information is connected and stored in a repository which allows real time updates and analysis.

The modeling is done with Microsoft Visio and is 
carried out directly from the Internet Explorer. Each graphical element becomes a content related object in SharePoint. Software as a Business Process Management solution provides you with an intuitive and centralized view of processes, organizational structures, and human activities.

The result is that operational processes within the organization are primarily taken into consideration. A correct linkage of operational and organizational structures and regulations are the basis for an integrated management system and his documentation as presented at the beginning of this paper.

\section{Modeling of products by DeCoDe}

Demand Compliant Design (DeCoDe) is a method, which has its root in the design for quality and has the goal of facilitating the design of a product system that meets all the specified demands [6].

In quality engineering, the primary focus is on customer demands. A product design needs to consider all the stages in the product life cycle, from the initial design to manufacturing, through its useful life, and to its final disposal. Over the product's life cycle, there are other stakeholders besides the customer (users) that have their own demands on the product, such as the various members of the organization that manufacture the product (owners, shareholders, and employees and more) and the persons and organization in the community affected by the product (see tabele 1). Therefore, the DeCoDe methods require that the demands from all the stakeholders be regarded and have to be made explicit and met in an effective way.

The requirements engineering (RE) provides techniques for eliciting, prioritizing, and administering requirements. DeCoDe takes the requirements obtained by RE techniques as inputs to guide the design process to achieve a demandcompliant product. It achieves this by making the relations between the demands, functions, components, and processes explicit and maintaining consistency and completeness at all stages of the design.

DeCoDe method comprises a product model, a set of tools, and a procedure (Figure 1). The product model consists of the following views of product:

- Requirement view - describes the requirements regarding the product.

- Functional view - describes product by the function it performs.

- Component view - describes the product by its parts and their relations.

- Process view - describes the product by the processes executed by and on the product during its life cycle.

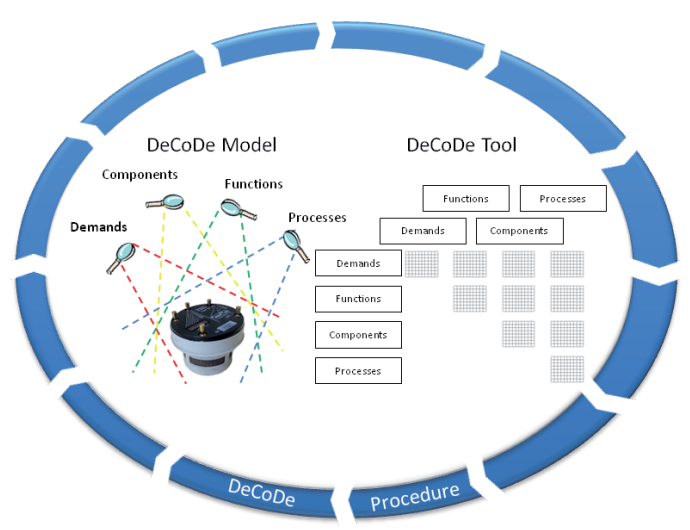

Fig. 1: DeCoDe Method [6].

The tools consist of the various dependence matrices and the demand, function, components and process catalogues that specify the product.

This method describes the whole of a complex product, finds out the gaps or the failures of a product and may create new solutions that are assessed against the demands for the selection of the best design. The DeCoDe method is a first step toward a formal description of the design task that will allow the application of quantitative techniques for solving the multiobjective design problem. The hallmark of the DeCoDe is the linking of the demands on the product with three complementary views of the product and maintenance of consistency at all the times as the design evolves.

\subsection{DeCoDe - Modeling with LOOMEO Software}

The DeCoDe method can be applied to a design task in different ways according to the maturity level of the current state of the design. Software LOOMEO from TESEON which focused on product models was used for this modeling.

This method is appropriate when starting a new design and only very demands are given. The method builds a demand list iteratively and concurrently with the function, component, and pro- 


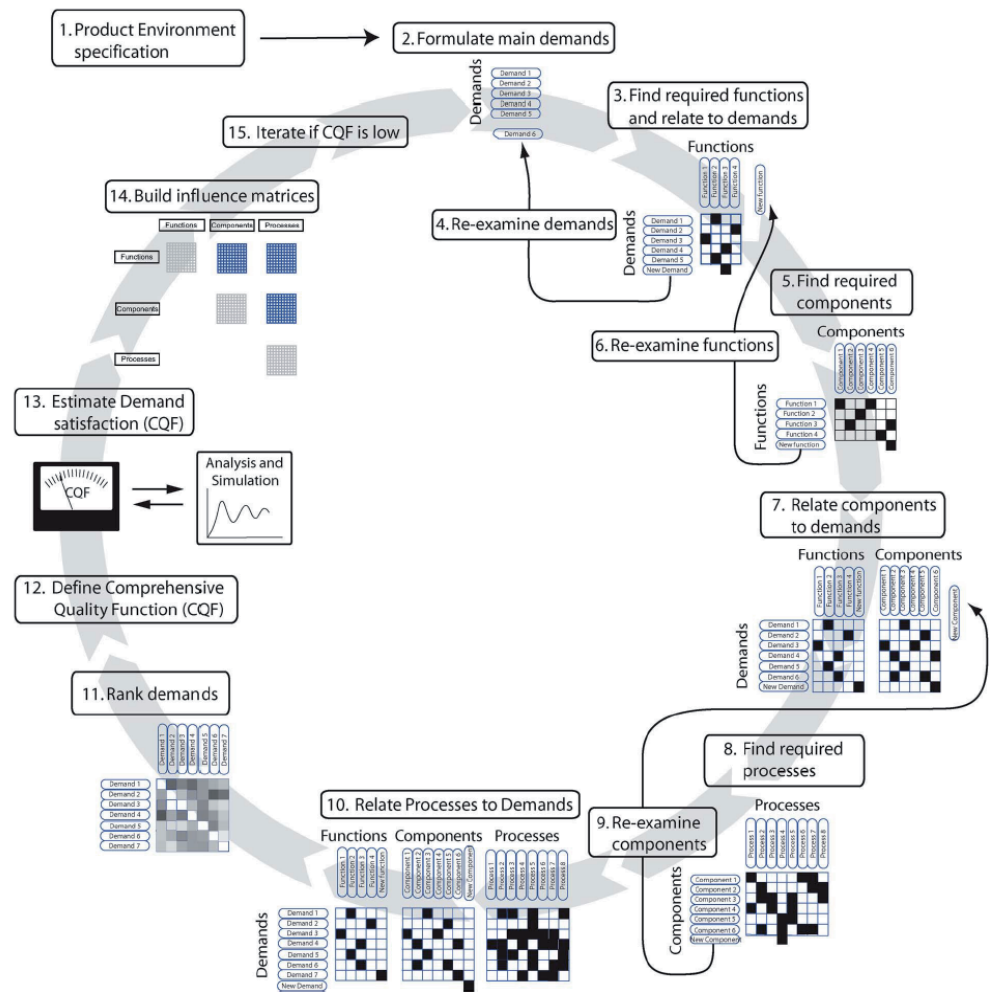

Fig. 2: Steps in DeCoDe method [6].

cess lists (see Figure 2). This paper will illustrate the method with the design of an optic smoke detector.

\section{Linking of IMS and Product models via processes}

Thus there is a need for linking IMS with the product requirements and their fulfillment by product characteristics to achieve a generic management system. This system has to link the product and its requirements (that are documented in a product system model), the IMS itself and the requirement management.

Requirements and demands in a product model express either a function or a constraint on one or more functions, components, or processes. The product model needs to perform these functions under the specified constraints. The performance of the required functions will be the result of the running of a collection of processes. In turn, the processes result from the dynamic interaction of the physical components of the product. Accordingly, the DeCoDe method takes three complementary views of a product. These views see the product as a collection of functions, a collection of processes, and a collection of components, all linked to the demands. Each view is represented by the corresponding list, or catalogue, of functions, processes, or components. The DeCoDe method uses matrices to capture and manipulate the relations between the requirements and the elements of the three product views. There are relations among the elements in each of the catalogues, and there are relations between the elements of different catalogues. These relations are captured in adjacency matrices. The rows of an adjacency matrix correspond to the entries in one catalogue and the columns to the entries in the same or another catalogue. There are ten such adjacency matrices as shown. The link of IMS with a product system model will be introduced in following chapter.

\section{Smoke detector Example}

An optical scattered light detector (see Figure 3) consists of a transmitter LED and a receiver photodiode. The two diodes are arranged in a certain angle to each other and visually separated by a diaphragm from each other so that they have no visual contact with each other.

The transmit LED emits infrared light into the measuring chamber. Penetration there in case of 
fire visible fire aerosol particles a. a portion of the light beam deflected by said particles and scattered towards the receiver (photo diode). The stray light results in a signal increase at the receiver. The receiver signal is evaluated by the detector electronics and triggers an alarm in case of fire.

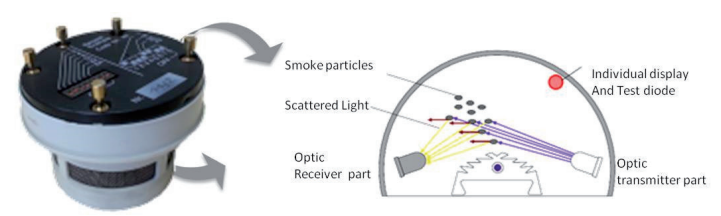

Fig. 3: Smoke detector.

Optical sensors based on this physical principle, can only detect visible fire aerosol particles. For fires with non-visible aerosols, such as Fire gases, optical scattered light detectors are not suitable.

We chose to use it as an example product model to illustrate the main steps of the DeCoDe procedure on a new design:

- Demands: The first thing to do is to phrase a brief overall description of the product. In this case, we choose the following:

An inexpensive optical smoke detector has to respond to increase concentration of visible smoke which affects the scattering or absorption of electromagnetic radiation in the infrared or ultraviolet visible part of spectrum. This main task of smoke detector allows us to derive a set of specific demands for the smoke detector. We will add other demands that are derived from marketing considerations. Therewith, we arrive at an initial demand set.

This list of demands should suffice at this early stage. The demands could be ordered by doing a pair wise comparison. However, this is better done after having determined the functions, components, and processes in a fist round as there may arise additional demands or modifications. Next what needs to be identified are the functions that the smoke detector has to perform to meet the demands.

- Functions: Some demands are constrining demands and, as such, do not translate into a function itself. The demands like "LED emits light modulated with frequency around $3 \mathrm{kHz}$ " or "resistibility towards false alarm" on the other hand require several functions.
- Components: The next step is to list the components required to provide the identified functions and satisfy rest demands. This optical (photoelectric) smoke detector includes following main components.

Now, the function-component matrix and the component-component influence matrix can also be built. The main matrices encapsulate some of the design knowledge at this state. This information can be recovered by reading the matrices. In particular, the row and column sums provide an easy interpretation. In the demand-component matrix, for example, the sum of a row indicates the influence of the corresponding demand on the whole design.

- Processes: There are two classes of processes. Those related to the life cycle of the product (its design, manufacture, deployment and disposal) and those processes that realize the purpose of the product. The components provide physical substrate for the processes that perform the functions that satisfy the demands. Therefore good starting points for listing the processes that are required is by going through the components list and identify which processes they participate. Going through the list, we can easily build the component-process matrix.

The processes of manufacturing the smoke detector have to be modeled as well. As those processes are needed for the IMS as well the basic idea is to link the product model with its requirements and the IMS that includes all requirements via this manufacturing process model.

In order to do so the first step is to model the manufacturing processes and then linking them with the product model.

\subsection{Manufacturing process modeling on selected example}

With the aim to create a manufacturing process model the software QUAM from LINTRA was used. It focuses on integrated management system modeling. For the need of this paper was created a model of smoke detector manufacturing processes in order to link them to the product model.

A suggested method allows connection of product components from product model (LOOMEO) with the manufacturing process steps (QUAM). Moreover, an approach has been created how to control all product model components in the process and at least which product requirements are fulfilled in this process. This approach allows con- 
trol a collection functions, a collection of processes and a collection of components, all linked to the requirements and assure a requirement-conform production.

\section{Conclusion}

Organizations which fail to meet all stakeholder requirements will quickly fall prey to competitors in the global market place. Success of the product is largely decided during its design phase and accordingly during the manufacturing phase. The main goal of the DeCoDe design method is to conduct the design activity in such a way that it leads to a demand-compliant product. This is achieved by mapping an initial set of requirements to three different views of the product like the functional view, the components view, and the process view. Matrices like a main tool of the DeCoDe method capture in a clear and easy-to-manipulate way the multitude of relations between these elements and assure that all functions, components, and processes are justified by the requirements and there is no unfilled requirement. Linking DeCoDe method and software dealing with modeling company in digital view via processes creating opportunity to identify and quantify processes by specified parameters. In such way a company improve organizational processes. This method, however, creates new issues. After linking IMS and product models the next step is to find a solution to integrate the organizational structure and responsibilities of processes as well as to digital manufacturing.

\section{Acknowledgments}

This contribution is the result of the project implementation KEGA - 049TUKE - 4/2014 " Designing a Model for E-learning Support of the Education in the Production Quality Bachelor Study Program".

\section{References}

[1] Hoyle, D.: Automotive Quality System Handbook: Incorporating ISO/TS 16949:2002. Second edition 2005. ISBN 0-7506-6663-3

[2] Pardy, W., Andrews, T.: Integrated management systems: Leading Strategies and Solutions. 2010. ISBN 978-0-86687196-0

[3] Prístavka, M., Hrubec, J., Bujna, M., Kotorová, M.: Quality control in production processes. 2011. ISBN 978-966-1507-76-9, s. $121-129$

[4] Sinay, J., Markulik, Š.: Môže byt kultúra kvality a kultúra bezpečnosti podmienkou prosperujúcej spoločnosti? Kosice, ISSN 1803-9138

[5] Sinay, J., Kamenicky, L.: Bezpečnost' a kvalita produkcie predpoklad pre integráciu v rámci manažérskych systémov. Ostrava 2013. ISBN 978-80-02-02463-7

[6] Sitte, J., Winzer, P.: Demand-Compliant Design, IEEE Transaction on system, man, and cybernetics- part A: sytems and humans, vol.41, No. 3, 2011

[7] Škưrková, K., Šesták, M.: The capacity of turning process by screws production, In: Production engineering. Novosibirsk : Novosibirsk State Technical University, 2009. S.49-56, ISBN 978-5-7782-1165-0.

[8] Thiele, J.: Entwickulng, Erprobung, Evaluierung und dauerhafte Etablierung eines forderungsgerechten integreirten Managementsystems, Shaker Verlag, Aachen, 2007. ISBN 978-3-8322-6345-4

[9] Winzer, P., Sinay, J.: From Integrated Management System towards Generic Management Systems - Approaches from Slovakia and Germany, Shaker Verlag, Aachen/BRD, 2009. ISBN 978-3-8322-8508-1

[10] Winzer, P.: Generic System Engineering, BU Wuppertal, 2013 ISBN 978-3-642-30365-4

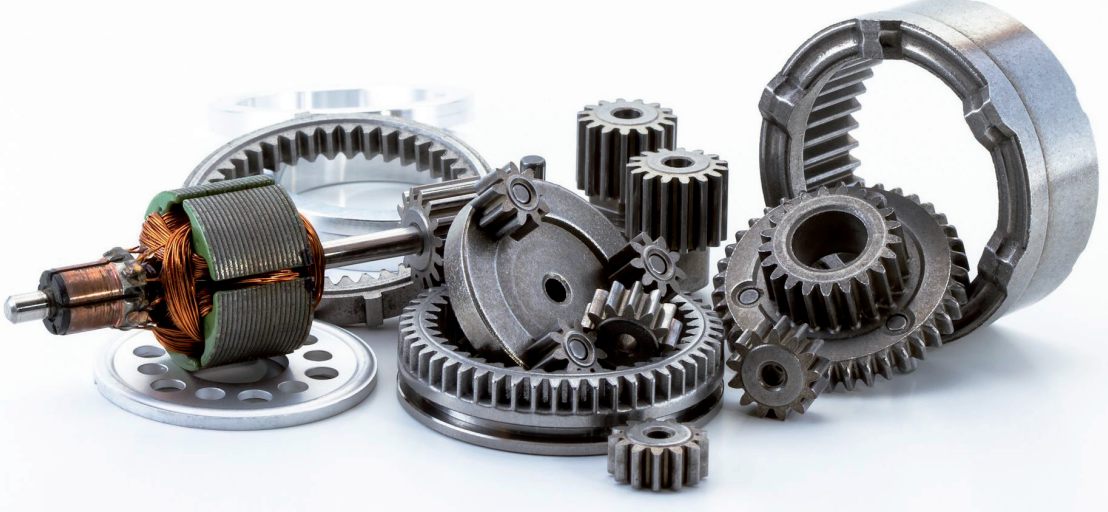

